\title{
ICOMOS-España celebra sus I Jornadas con el lema patrimonio, desarrollo y comunidad local
}

Fue el pasado día 15 de marzo. En Barcelona, en el Museo de Historia de Cataluña. Las Jornadas ICOMOS-España tenían el objetivo expreso de articular redes, generar sinergias y desarrollar planes de acción conjuntos para la defensa y protección del patrimonio cultural. Haciendo coincidir estas I Jornadas con la celebración de la Asamblea General ordinaria de ICOMOS-España, el programa incluyó la presentación del proyecto estratégico 2018-2021 de la entidad y dos mesas redondas: en la primera de ellas, dirigida a profesionales relacionados con el patrimonio cultural, se abordaron los nuevos horizontes del patrimonio cultural en la actualidad; en la segunda, focalizada en las asociaciones patrimoniales, uno de estos horizontes específico, el turismo y el patrimonio cultural. Xavier Casanovas y Ana Yáñez Vega moderaron cada una de estas mesas respectivamente. En estas páginas, comparten las ideas debatidas en ambos foros.

Xavier Casanovas | miembro de la junta directiva de ICOMOS.es

Ana Yáñez Vega | secretaria general de ICOMOS-España

URL de la contribución <http://www.iaph.es/revistaph/index.php/revistaph/article/view/4403>

El patrimonio cultural hoy: Nuevos conceptos, nuevos desafíos

El objeto de esta mesa surgió de la constatación de un cierto desconocimiento, incluso entre los miembros de ICOMOS, de la diversidad temática que hoy en día abarca el concepto de patrimonio cultural. ICOMOS aglutina actualmente una gran diversidad de expertos multidisciplinares en patrimonio cultural desde las más diversas vertientes; más allá de los arquitectos, encontramos historiadores, arqueólogos, documentalistas, abogados, ingenieros, químicos, geólogos, economistas y muchos otros profesionales que el patrimonio requiere.

Los casi 30 comités científicos internacionales de ICOMOS suponen hoy el punto de encuentro de especialistas en diferentes ámbitos, para desarrollar los principios, las técnicas y las políticas de salvaguarda y puesta en valor del patrimonio cultural. Echando un vistazo a estos comités, nos damos cuenta de que algunos de ellos afrontan, de forma especializada, componentes específicos de los monumentos y sus materiales (estructuras, madera, piedra, vidrieras, pinturas murales...), modelos tipológicos (arquitectura tradicional, de tierra, del siglo XX, fortificaciones, ciudades históricas...) o aspectos instrumentales (economía, prevención de riesgos, energía y sostenibilidad, documentación...). Así mismo, otros comités se orientan a temas más alejados del monumento en sí mismo, como arqueología, arte rupestre, itinerarios culturales, formación, turismo cultural, entre otros.

Para debatir sobre estos temas y plantear los nuevos desafíos, se contó con la participación de cuatro expertos con especialidades diferenciadas y complementarias:

En primer lugar, Margarita Díaz-Andreu (arqueóloga del Grup d'Arqueologia Publica i Patrimoni GAPP de la Universitat de Barcelona y miembro de ICOMOS) aportó su visión de las múltiples posibilidades que la arqueología, como ciencia y como patrimonio arqueológico, ofrece en la dinamización cultural y social.

La arqueología en sí misma es todo un mundo o sector cultural. Hasta hace unos años centrado en los museos y en las universidades, y en el estudio de culturas lejanas en el tiempo. Desde finales del siglo XX, la arqueología se ha integrado en la actividad de transformación de la ciudad, con la integración de arqueólogos en equipos multidisciplinares, con la arqueología preventiva y de gestión, lo que la convierte en una herramienta de 


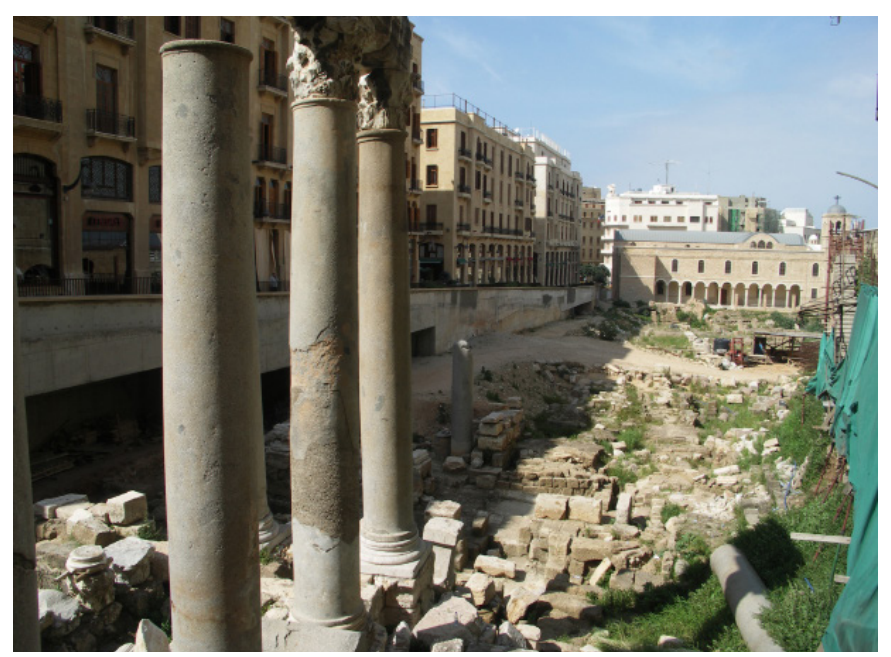

La integración y puesta en valor del patrimonio arqueológico alcanza cada día mayor protagonismo y presencia en las ciudades. Beirut (Líbano) | foto todas las imágenes que ilustran esta contribución son de Xavier Casanovas

conocimiento esencial en las intervenciones en los tejidos urbanos consolidados y en los monumentos. Así mismo, el patrimonio arqueológico está cada día más presente en la ciudad y en la sociedad con la implicación de la sociedad civil en las excavaciones arqueológicas, organización de visitas y todo tipo de actividades para el refuerzo de la cohesión social.

A continuación, el ingeniero de caminos Pere Roca, de la Universitat Politècnica de Catalunya y también miembro de ICOMOS, planteó cinco retos esenciales que hoy plantea el estudio y la conservación de las estructuras históricas:

> Limitada aplicabilidad de la normativa actual, pensada para los edificios de nueva construcción, hecho que comporta tener que trabajar sin apoyo en un cuerpo legal. Afortunadamente, recomendaciones como las del Comité ISCARSAH (estructuras históricas) sirven de apoyo a la toma de decisiones;

$>$ Restricciones en la toma de datos, donde se contrapone el respeto al valor cultural del monumento con los datos disponibles para la diagnosis y la verificación estructural. > Disponer de métodos asequibles para la diagnosis y poder adecuar el coste de los estudios a las necesidades reales de conocimiento.

$>$ Establecer criterios objetivos de evaluación del impacto de las intervenciones sobre la autenticidad y valor cultural, contraponiéndolo con los beneficios que la intervención reporta al monumento.

$>$ Diseñar intervenciones que no sólo minimicen el impacto sobre el valor cultural, sino que lo incrementen con un efecto positivo o favorable.

Por su parte, Lluís Garcia Petit, licenciado en Geografía e Historia y Director del Institut del Patrimoni Cultural Inmaterial (IPACIM), desde su larga experiencia en este ámbito, comentó cómo ya en los años '80 se identificó el patrimonio inmaterial por su valor identitario y social. Ello fue consecuencia del reconocimiento de la diversidad cultural del planeta, definida a menudo por elementos inmateriales, vinculados a la cultura tradicional, al folklore, a la etnografía y etnología, entre otros, y supuso una nueva mirada sobre el patrimonio cultural.

La convención del patrimonio inmaterial lo reconoce como usos, representaciones, expresiones, conocimientos y técnicas, junto con los objetos y espacios inherentes. Ello conlleva algunos retos esenciales:

> La comunidad debe decidir qué es y qué forma parte de su patrimonio inmaterial.

$>$ El patrimonio inmaterial mantiene un vínculo directo con algunos elementos del patrimonio material, con el cual se debe establecer una relación y un equilibrio.

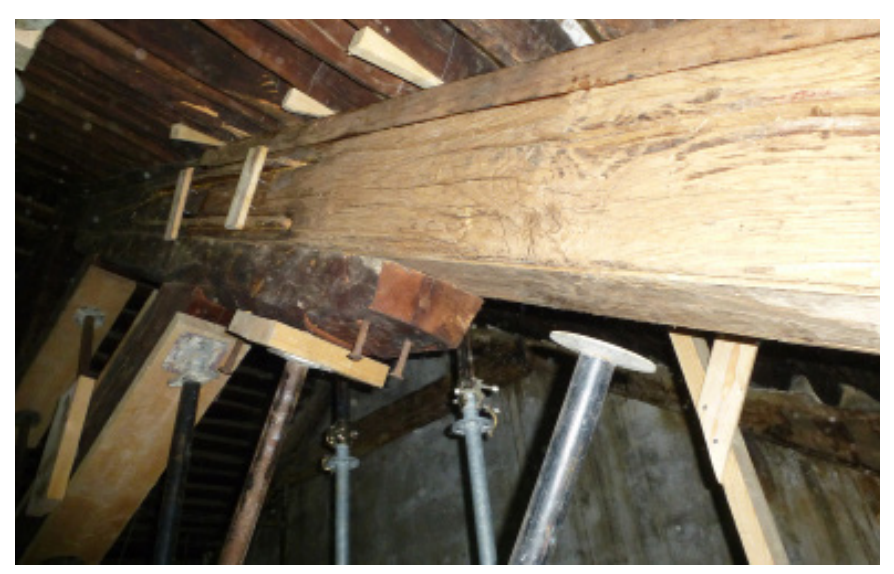

Más allá del edificio en toda su integridad, sus elementos estructurales tienen un valor propio a preservar. Restauración de la estructura de la cubierta de la Iglesia de la Natividad, Belén (Palestina) 
Finalmente, Mónica Luengo, historiadora del arte, paisajista y vicepresidenta de ICOMOS.es, incidió sobre el paisaje como un patrimonio común natural y cultural de gran valor identitario para la sociedad y su entorno. Paisaje como resultado del trabajo combinado de la naturaleza y el hombre, que ilustra la evolución de la sociedad humana, y un monumento a los trabajadores anónimos que lo han conformado con su trabajo en el tiempo.

Ya en 1992 se establecieron unas directrices que clasificaron los paisajes culturales en tres tipos:

> Paisaje diseñado, concebido y creado de forma intencionada (jardines, parques...).

> Paisaje evolutivo, resultado de las exigencias sociales, económicas, administrativas, religiosas o de otro tipo. En este caso se distinguen dos tipos: fósil y vivo.

> Paisaje asociativo, como resultante de una asociación de fenómenos religiosos, artísticos o culturales.

Los principales retos se pueden resumir en tres:

$>\mathrm{Su}$ gran escala, normalmente integrados en un contexto más amplio.

$>$ Gran diversidad y número de actores implicados y que intervienen o interactúan con el paisaje, o incluso que forman parte de él.

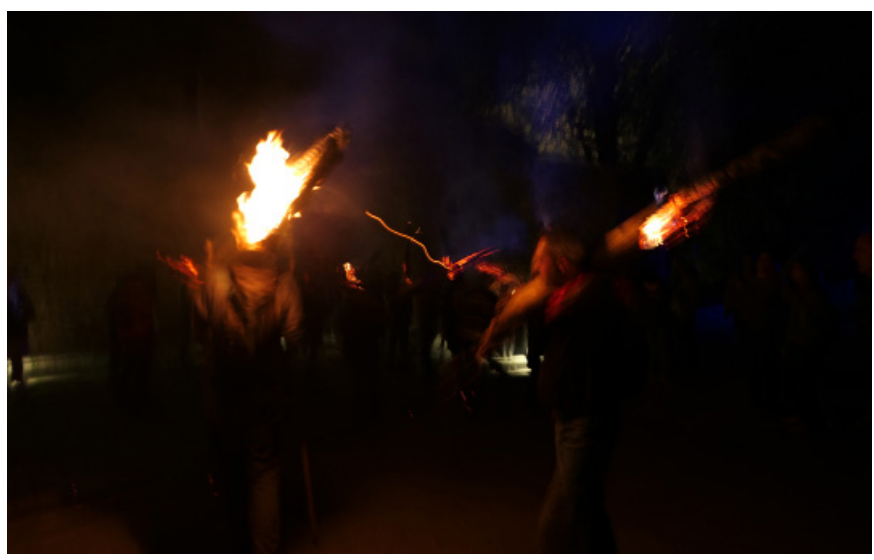

El patrimonio inmaterial es el más vulnerable, pero también el más vinculado a los valores identitarios de la comunidad. Fallas de Sant Joan d'Isil, Catalunya (España)

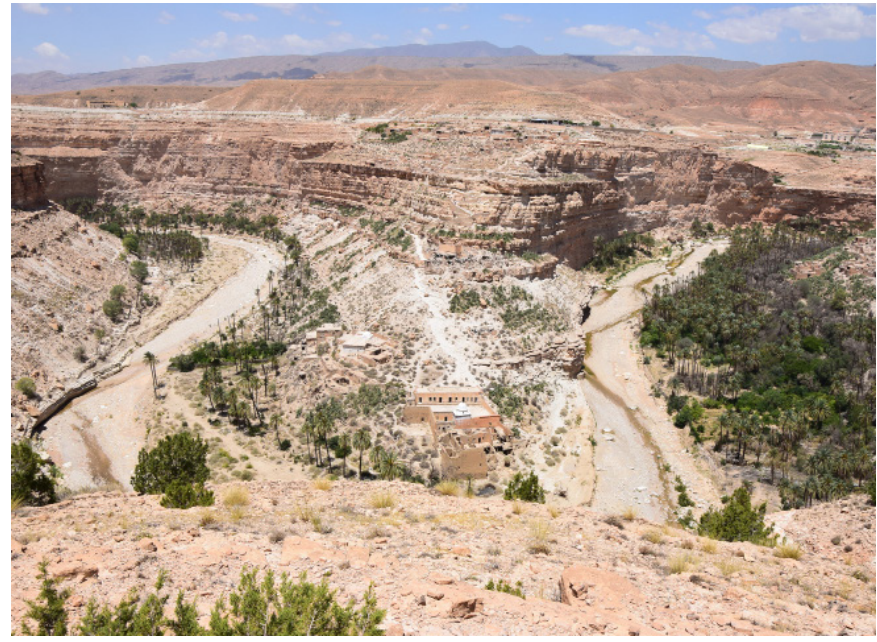

La diversidad de paisajes naturales y humanizados les da un gran valor cultural a pesar de su gran fragilidad. Goufi, Aurès, Argelia

$>$ Los cambios intrínsecos de los paisajes, formados en muchos casos por seres vivos, que requieren de una gestión cuidadosa de los mismos, para preservar y respetar sus valores.

Podemos concluir del debate que el concepto de patrimonio cultural es relativamente reciente y que va ampliando progresivamente sus ámbitos, desde el objeto de memoria (monumento), al objeto de valor estético y artístico, a la función identitaria, al valor económico y muchos más aspectos que conforman hoy una visión holística del patrimonio cultural. Así mismo, cabe destacar la obligada interrelación entre las diferentes disciplinas, las cuales se articulan hoy en los necesarios equipos multidisciplinares.

\section{Patrimonio cultural y turismo. Retos y oportunidades} Centrando la atención en la mesa redonda 2, su finalidad fue presentar diferentes miradas sobre el patrimonio cultural y el turismo. En todo momento se pretendió que esas perspectivas fueran diversas, tanto como lo son las situaciones que se plantean en este contexto. Así, participaron en la misma tanto expertos de la esfera pública como de la privada; pertenecientes a ICOMOS-España así como externos a nuestra institución e incidiendo en cuestiones de ámbito nacional e internacional. Esta conjunción de miradas consiguió posteriormente un debate muy interesante entre el público y los miembros de la mesa. 
En la parte central intervinieron Damià Martínez, jefe del Àrea de Programes Públics de l'Agència Catalana de Patrimoni Cultural (Generalitat de Catalunya) y seguidamente Laura Pastor e Isabel Vallès, gestoras de Cases Singulars. Damià Martínez puso de manifiesto cómo la Agència Catalana de Patrimoni Cultural contempla entre sus objetivos específicos algunos vinculados directamente con el turismo: fomentar el uso del patrimonio cultural y de los equipamientos culturales, prestando una atención especial a la educación y al turismo cultural en colaboración con el departamento competente en materia de turismo; mejorar la vinculación con la comunidad y la internacionalización y fomentar las prácticas asociadas a la conservación y divulgación de este patrimonio. Otros de los fines de la Agència también pueden relacionarse de forma muy estrecha con el turismo: dinamizar el patrimonio cultural mediante la cooperación entre agentes públicos y privados y fomentar la vinculación del patrimonio cultural con el desarrollo territorial y paisajístico y el desarrollo económico, para generar recursos destinados a la promoción y la conservación de dicho patrimonio.

Por su parte, Laura Pastor e Isabel Vallès expusieron a los asistentes la apuesta que hicieron en el año 2010 cuando crearon Cases Singulars, entidad con la que han explicado al público la historia de Barcelona a través de las casas de sus protagonistas y bajo el deseo de hacer más accesible un patrimonio desconocido hasta la fecha. Desde Cases Singulars siempre se ha apostado por un turismo cultural sostenible; ejemplo de ello es cómo, coincidiendo con su noveno aniversario, ha ampliado sus actividades culturales y se ha propuesto descubrir algunas de las casas museo más desconocidas del patrimonio catalán, mostrando una casa cada día.

Abrieron y cerraron la mesa redonda miembros de la Junta Directiva de ICOMOS-España: Celia Martínez Yáñez, de la Universidad de Granada, secretaria general adjunta de ICOMOS-España y vicepresidenta del Comité Científico Internacional de Turismo Cultural de ICOMOS; y Jordi Tresserras, de la Universitat de Barcelona, vicepresidente de ICOMOS-España y consultor UNESCO del Programa Patrimonio Mundial y Turismo Sostenible. Ambos dieron una perspectiva internacional a sus inter- venciones, fruto de su experiencia y de la configuración del Consejo Internacional de Monumentos y Sitios, del que ICOMOS-España forma parte, como una asociación internacional. Así, Celia Martínez Yáñez dio cuenta de la revisión que se está realizando de la Carta Internacional de Turismo Cultural de Icomos (1999); el crecimiento imparable del turismo en las dos últimas décadas demanda un estudio profundo y nuevos instrumentos y medidas para ampliar o reducir, según el caso, los impactos positivos o negativos. Se espera que a finales del próximo año 2020 el Consejo Internacional de Monumentos y Sitios pueda adoptar un documento actualizado que refleje las complejas perspectivas del binomio protección de bienes culturales y gestión de visitantes. Por su parte, Jordi Tresserras realizó un análisis sobre la inclusión del turismo y el patrimonio cultural en los Objetivos de Desarrollo Sostenible (ODS), en la Nueva Agenda Urbana (Habitat III) y en el Programa UNESCO de Patrimonio Mundial y Turismo Sostenible. Entre los ODS destacan los números 8 (promover el crecimiento económico sostenido, inclusivo y sostenible, el empleo pleno y productivo y el trabajo decente para todos), 11 (lograr que las ciudades y los asentamientos humanos sean inclusivos, seguros, resilientes y sostenibles) y 12 (garantizar modalidades de consumo y producción sostenibles); los tres incluyen metas específicas sobre turismo sostenible y patrimonio cultural.

Tras este recorrido, la mesa concluyó no sin antes abrir un interesante debate en el que temas como la gentrificación y la turismofobia, tan identificables en la gestión de diferentes espacios protegidos por sus valores históricos, estuvieron presentes y provocaron apasionadas intervenciones del público.

Las I Jornadas se clausuraron con una reunión de entidades patrimoniales e ICOMOS-España con el fin de articular redes, generar sinergias y desarrollar una estrategia y planes de acción conjuntos; de esta forma y más allá de la reunión con sus miembros, el Comité Nacional Español pretende conocer de primera mano la realidad de las instituciones que trabajan en la protección, defensa y conservación de nuestros bienes culturales; y hacer realidad los conceptos clave de su proyecto estratégico: compromiso, crecimiento y disfrute. 